\title{
Clinical Presentation of Tubulointerstitial Nephritis Caused by Amyloid Light-chain Amyloidosis in a Patient with Sjögren's Syndrome
}

\author{
Reiko Inoue ${ }^{1}$, Yoshihide Fujigaki ${ }^{1}$, Kana Kobayashi ${ }^{1}$, Yoshifuru Tamura ${ }^{1}$, Tatsuru Ota ${ }^{1}$, \\ Shigeru Shibata ${ }^{1}$, Tsuyoshi Ishida ${ }^{2}$, Fukuo Kondo ${ }^{2,3}$, Yutaka Yamaguchi ${ }^{3}$ and Shunya Uchida ${ }^{1}$
}

\begin{abstract}
We report a 70-year-old woman with Sjögren's syndrome who had severe renal dysfunction with mild proteinuria and elevated urinary low-molecular-weight proteins. Based on these clinical presentations, interstitial nephritis due to Sjögren's syndrome was strongly suspected. Unexpectedly, renal pathology revealed amyloid light-chain (AL) lambda-type depositions predominantly in the vasculatures with severe tubulointerstitial damage. Concentrated urine immunofixation was positive for Bence Jones lambda-type monoclonal proteins. Given the involvement in other organs, systemic AL amyloidosis was diagnosed. The patient underwent chemotherapy, but hemodialysis was ultimately instituted. It should be remembered that renal amyloidosis occurs as a clinical presentation of interstitial nephritis.
\end{abstract}

Key words: amyloid light-chain (AL) amyloidosis, Sjögren's syndrome, interstitial nephritis

(Intern Med 56: 419-423, 2017)

(DOI: 10.2169/internalmedicine.56.7548)

\section{Introduction}

Amyloidosis is not an unusual cause of proteinuria in elderly patients. The main clinical presentation of renal amyloidosis is massive proteinuria, often in the nephrotic range, and it is important for clinicians to suspect amyloidosis in the course of the investigation of proteinuria. However, some cases with renal amyloidosis are characterized by progressive renal dysfunction rather than proteinuria; a proteinuria-absent case has even been reported (1). Because its clinical manifestation varies, probably according to the site and degree of amyloid deposition (2), renal amyloidosis has the potential to be clinically misdiagnosed in patients without a large amount of proteinuria.

We herein report a case of biopsy-proven systemic amyloid light-chain (AL) amyloidosis who had mild proteinuria and severe renal dysfunction and was initially suspected of having interstitial nephritis caused by Sjögren's syndrome.

\section{Case Report}

A 70-year-old Japanese woman visited our department with a complaint of leg edema. She had no history of hypertension or diabetic mellitus, but she had experienced a transient cardiac failure episode four months prior that could not be further investigated. When she had received left femoral head replacement surgery for the fracture three months prior, anemia and an elevated serum creatinine level of $1.89 \mathrm{mg} /$ $\mathrm{dL}$ had been noted. She was positive for antinuclear antibody and had slight hypocomplementemia, so she was referred to the Division of Rheumatology at our hospital. She did not meet the criteria of Systemic Lupus International Collaborating Clinics (SLICC) classification for diagnosing systemic lupus erythematosus (3). She had a complaint of dry eye but did not have dry mouth symptoms. Since she did not show any symptoms or laboratory data suggestive of other autoimmune diseases, such as rheumatoid arthritis, dermatomyelitis, or scleroderma, the finding of positive anti-

${ }^{1}$ Department of Internal Medicine, Teikyo University School of Medicine, Japan, ${ }^{2}$ Department of Pathology, Teikyo University Hospital, Japan and ${ }^{3}$ Department of Pathology, Teikyo University School of Medicine, Japan

Received for publication April 7, 2016; Accepted for publication June 2, 2016

Correspondence to Dr. Yoshihide Fujigaki, fujigaki@med.teikyo-u.ac.jp 
Table. Laboratory Data on Admission.

\begin{tabular}{|c|c|}
\hline \multicolumn{2}{|l|}{ Urinalysis } \\
\hline Gravity & 1.012 \\
\hline $\mathrm{pH}$ & 6 \\
\hline Protein & $2+$ \\
\hline Glucose & $(-)$ \\
\hline Occult blood & $1+$ \\
\hline \multicolumn{2}{|l|}{ Sediments } \\
\hline Red blood cell count & 5-9/high power field \\
\hline White blood cell count & 1-4/high power field \\
\hline \multicolumn{2}{|l|}{ Urine chemistry } \\
\hline $\mathrm{Na}$ & 77 mEq/L \\
\hline Creatinine & $69.7 \mathrm{mg} / \mathrm{dL}$ \\
\hline Protein & $87 \mathrm{mg} / \mathrm{dL}$ \\
\hline NAG & $13.4 \mathrm{U} / \mathrm{L}$ \\
\hline$\beta 2$-microglobulin & $51,775 \mu \mathrm{g} / \mathrm{L}$ \\
\hline$\alpha 1$-microglobulin & $141 \mathrm{mg} / \mathrm{L}$ \\
\hline \multicolumn{2}{|l|}{ Complete blood count } \\
\hline White blood cells & $3,000 / \mu \mathrm{L}$ \\
\hline $\mathrm{Hb}$ & $10.6 \mathrm{~g} / \mathrm{dL}$ \\
\hline Platelets & $18 \times 10^{4} / \mu \mathrm{L}$ \\
\hline \multicolumn{2}{|l|}{ Blood chemistry } \\
\hline Total protein & $6.8 \mathrm{~g} / \mathrm{dL}$ \\
\hline Albumin & $4.0 \mathrm{~g} / \mathrm{dL}$ \\
\hline Urea nitrogen & $74.6 \mathrm{mg} / \mathrm{dL}$ \\
\hline Creatinine & $4.53 \mathrm{mg} / \mathrm{dL}$ \\
\hline Uric acid & $10.4 \mathrm{mg} / \mathrm{dL}$ \\
\hline $\mathrm{Na}$ & $140 \mathrm{mEq} / \mathrm{L}$ \\
\hline K & $4.9 \mathrm{mEq} / \mathrm{L}$ \\
\hline $\mathrm{Cl}$ & $103 \mathrm{mEq} / \mathrm{L}$ \\
\hline $\mathrm{Ca}$ & $8.6 \mathrm{mg} / \mathrm{dL}$ \\
\hline $\mathrm{Pi}$ & $6.3 \mathrm{mg} / \mathrm{dL}$ \\
\hline estimated GFR & $8.1 \mathrm{~mL} / \mathrm{min} / 1.73 \mathrm{~m}^{2}$ \\
\hline \multicolumn{2}{|l|}{ Serology } \\
\hline $\operatorname{IgG}$ & $959 \mathrm{mg} / \mathrm{dL}$ \\
\hline $\operatorname{IgA}$ & $175 \mathrm{mg} / \mathrm{dL}$ \\
\hline $\operatorname{IgM}$ & $43 \mathrm{mg} / \mathrm{dL}$ \\
\hline $\mathrm{CH} 50$ & $40 \mathrm{U} / \mathrm{mL}$ \\
\hline $\mathrm{C} 3$ & $56 \mathrm{mg} / \mathrm{dL}$ \\
\hline $\mathrm{C} 4$ & $15 \mathrm{mg} / \mathrm{dL}$ \\
\hline C-reactive protein & $0.45 \mathrm{mg} / \mathrm{dL}$ \\
\hline Antinuclear antibody & $\times 1,280$ speckled \\
\hline Anti-DNA antibody & $<0.5 \mathrm{IU} / \mathrm{mL}(<9.0)$ \\
\hline Anti-SS-A antibody & $<240 \mathrm{U} / \mathrm{ml}(<6.0)$ \\
\hline MPO-ANCA & $<1.0 \mathrm{U} / \mathrm{mL}(<3.4)$ \\
\hline PR3-ANCA & $<1.0 \mathrm{U} / \mathrm{mL}(<3.4)$ \\
\hline \multicolumn{2}{|c|}{$\begin{array}{l}\text { GFR: glomerular filtration rate, MPO-ANCA: } \\
\text { myeloperoxidase-anti-neutrophil cytoplasmic antibody, } \\
\text { PR3-ANCA: proteinase 3-anti-neutrophil cytoplasmic } \\
\text { antibody } \\
\text { The values in parentheses show the normal range. }\end{array}$} \\
\hline
\end{tabular}

SS-A antibody in association with a positive gum test and Schirmer's tear test prompted a diagnosis of primary Sjögren's syndrome. Her serum creatinine level had increased to $4.53 \mathrm{mg} / \mathrm{dL}$, so she was admitted to the Division of Nephrology for further investigation.

On admission, her height was $154.0 \mathrm{~cm}$, weight $44.9 \mathrm{~kg}$, blood pressure of $124 / 70 \mathrm{mmHg}$, pulse rate of $74 / \mathrm{min}$, and body temperature $36.5^{\circ} \mathrm{C}$. A physical examination revealed no remarkable findings except for mild pitting edema in both legs. The laboratory data on admission are shown in the Table. The hemoglobin level was $10.6 \mathrm{~g} / \mathrm{dL}$ under erythropoietin-stimulating agent therapy. A urine examination showed $2+$ protein, $1+$ occult blood in the dip stick, and $0.4 \mathrm{~g}$ of protein in 24-hour urine collection. The levels of urinary low-molecular-weight proteins (alpha 1- microglobulin and beta 2-microglobulin) were markedly elevated, and urinary $\mathrm{N}$-acethyl- $\beta$-D-glucosaminidase (NAG) was slightly elevated, indicating the presence of tubulointerstitial damage. Anti-neutrophil cytoplasmic antibody was negative, and serum immunoelectrophoresis, used in the diagnostic evaluation for AL amyloidosis, showed no monoclonal components. Therefore, we strongly suspected interstitial nephritis due to Sjögren's syndrome as a possible cause of the rapid deterioration of the renal function.

Renal biopsy performed a week after admission showed 7 globally sclerosed glomeruli out of 20,2 glomeruli with mild mesangial expansion, and the remaining 11 glomeruli had massive nodular lesions at the vascular pole, extending to the mesangial areas with weak positive periodic acidSchiff (PAS) staining (Fig. 1A). The arteries and arterioles were replaced with weakly PAS-positive deposits throughout the layers, and their lumen were severely stenosed or occluded (Fig. 1A). Tubular atrophy and interstitial fibrosis with mononuclear cell infiltration were found in about $70 \%$ of tubulointerstitial areas, with the occasional presence of tubulitis (Fig. 1A). Congo-red staining showed positivity in the areas corresponding to weakly PAS-positive deposits (Fig. 1B). In an immunofluorescence study, IgA, IgG, Clq, and $\mathrm{C} 3$ were negative, but IgM was positive at the nodular regions of glomeruli. Kappa light chain was negative, but lambda light chain was strongly positive in the arterial walls and the glomeruli (Fig. 1C). Amyloid A (AA) was negative. Electron microscopy revealed amyloid fibrils in the mesangial areas (Fig. 1D) and the glomerular capillary walls. Renal AL amyloidosis was therefore diagnosed.

Repeated immunofixation electrophoresis using concentrated urine and serum immunofixation turned out to be positive for Bence Jones lambda-type monoclonal proteins. The serum kappa/lambda free light chains ratio was 0.18 , indicating elevated lambda light chain. Bone marrow aspiration showed 4\% plasma cells. Gastroduodenal biopsy could not prove amyloid deposition, probably because the biopsy specimens did not contain the muscular layer. However, diffuse low voltage in the electrocardiogram (Fig. 2A) and granular sparkling sign of the thickened ventricular septum $(16 \mathrm{~mm})$ with severely impaired systolic/diastolic function on cardiac ultrasonography (Fig. 2B) indicated the presence of cardiac amyloidosis (4). In addition, abdominal wall fat aspiration was positive for direct fast scarlet staining in the small artery walls (Fig. 3). Systemic AL amyloidosis with lambda light chain type was ultimately diagnosed.

Given that the renal function continued to deteriorate, hemodialysis was introduced seven weeks after admission. Chemotherapy with melphalan and dexamethason was initiated. The kappa/lambda ratio normalized to 0.57 , but her renal function did not improve, and she ultimately began maintenance hemodialysis.

\section{Discussion}

The major renal histopathological findings of Sjögren's 


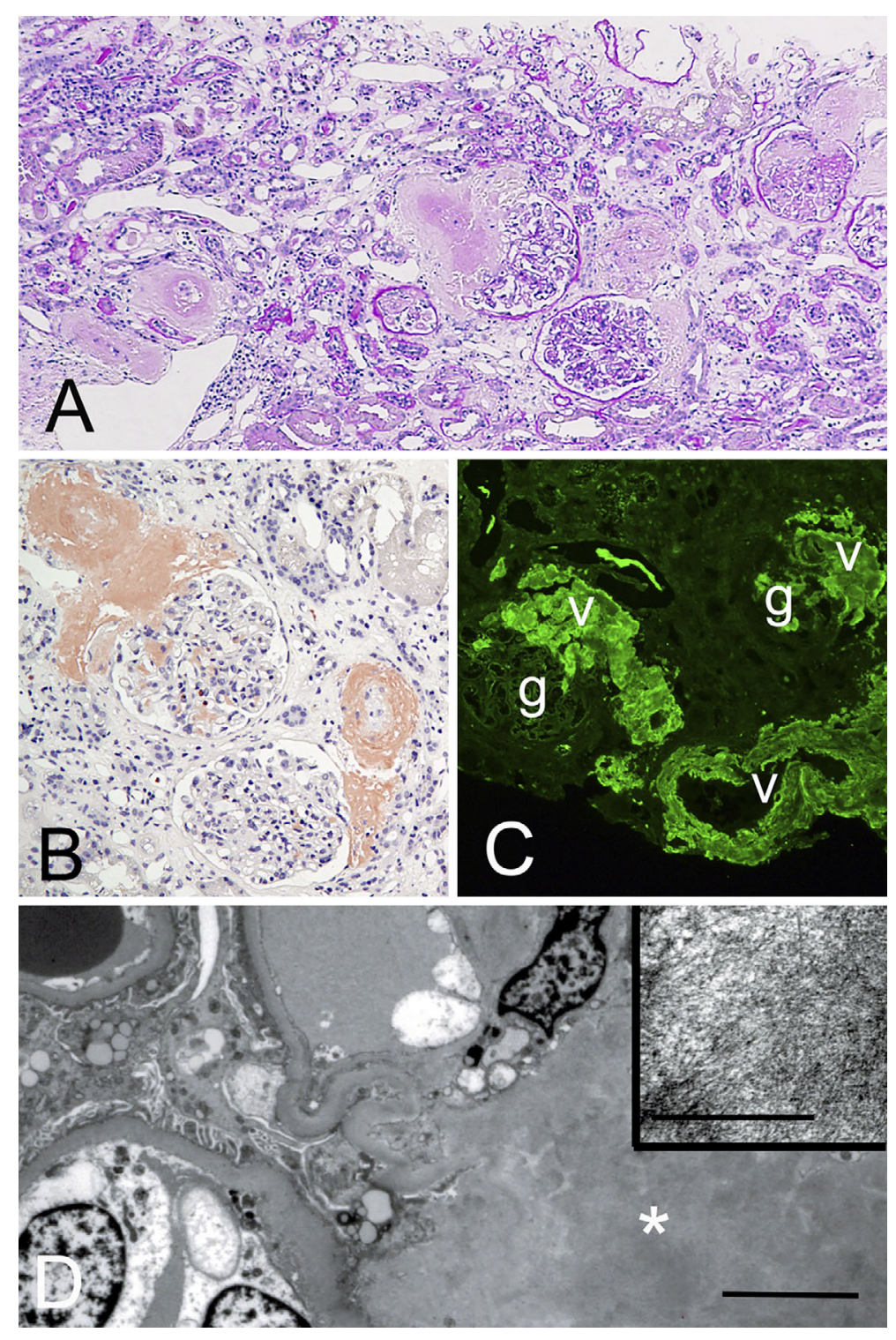

Figure 1. The microscopic findings on renal biopsy. A: periodic acid-Schiff (PAS) staining shows massive nodular lesions at the vascular pole of glomeruli extending to the mesangial areas with weakly positive PAS staining. The arteries and arterioles were replaced with weakly PAS-positive materials throughout the layers, and the lumen was severely stenosed or occluded. Atrophic tubules and interstitial fibrosis were present, with moderate mononuclear cell infiltration and slight tubulitis (original magnification, 200x). B: Congo-red staining shows positivity in weakly PAS-positive lesions in glomeruli, arterioles, and small arteries, as well as in some interstitial areas (original magnification, 200x). C: Immunofluorescence for lambda shows positivity on massive nodular lesions at the vascular pole of the glomerulus extending to the mesangial area and small arteries. g: glomerulus, v: vasculature (original magnification, 200x) D: Electron microscopy shows amyloid deposition at the mesangial area $(*)$, with randomly disposed amyloid fibrils on higher magnification (inset, Bar=0.5 $\mu \mathrm{m}$ ). Bar $5 \mu \mathrm{m}$.

syndrome are acute or chronic tubulointerstitial nephritis, with chronic tubulointerstitial nephritis the most common presentation associated with urine-concentration and urineacidification defects (5). Our case had no episodes of nocturia implicating urine-concentration impairment, and her renal failure was so severe that the existence of a urineacidification defect could not be evaluated. However, the extremely high levels of urinary low-molecular-weight proteins with mild proteinuria (0.4-0.5 g/day) and microscopic hema- turia in our case strongly indicated that the major damaged site was the tubulointerstitial area. Interstitial nephritis associated with Sjögren's syndrome was suspected before renal biopsy. Unexpectedly, renal biopsy revealed renal AL amyloidosis. Low concentrations of lambda-type monoclonal proteins in this patient may be the reason why serum immunoelectrophoresis did not show monoclonal components before renal biopsy. However, it is unknown whether or not this relates to primary Sjögren's syndrome or the $4 \%$ plasma 


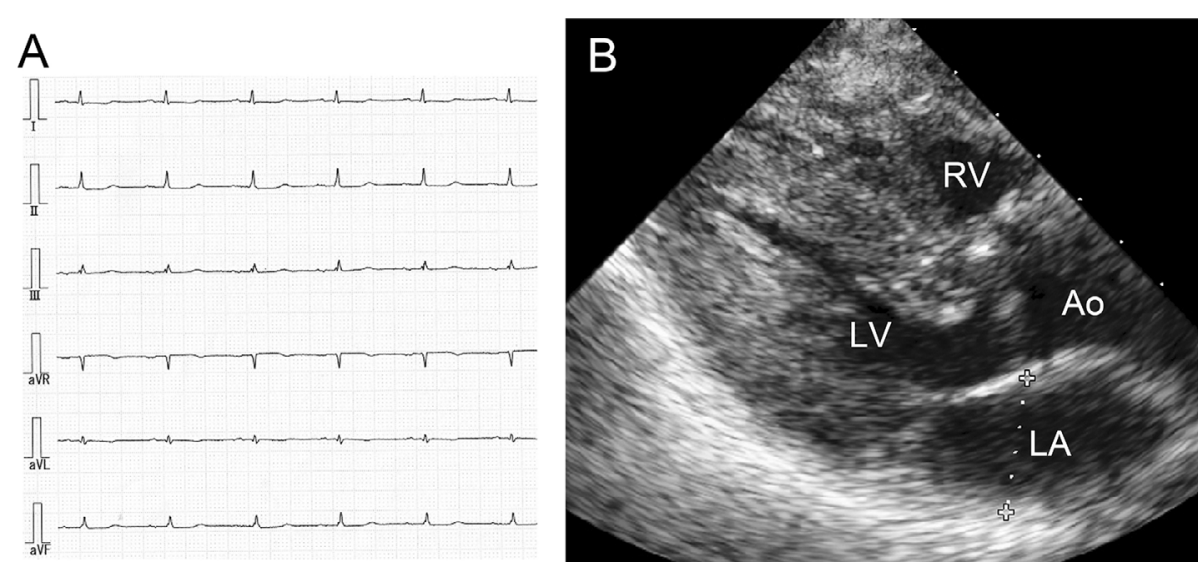

Figure 2. A: Electrocardiogram showing low-voltage QRS complexes in limb leads. B: Echocardiogram showing thickened ventricular walls and a thickened ventricular septum with nonhomogenous granular sparking echoes. LV: left ventricle, RV: right ventricle, LA: left atrium, Ao: aortic outflow

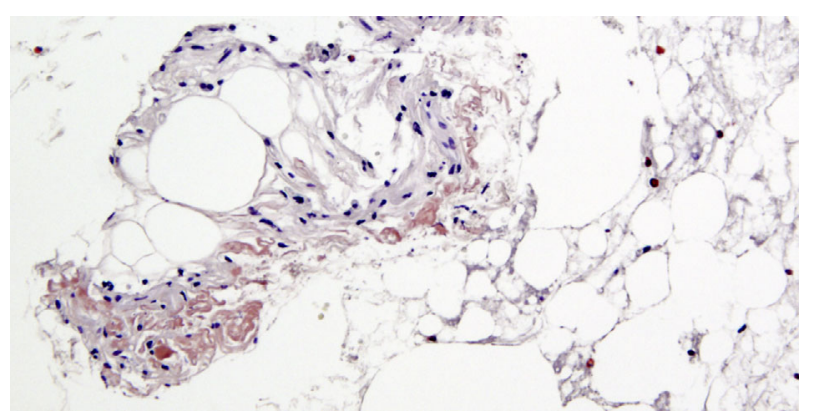

Figure 3. Direct fast scarlet staining shows positivity in the small artery walls in abdominal wall fat tissue (original magnification, 200x).

cells in the bone marrow.

The major target of amyloid deposition in the kidney is the glomeruli. Roughly $97-100 \%$ of AL and AA renal amyloidosis patients have glomerular amyloid deposition (6-9). Several reports have shown that massive or global deposition of amyloid in the glomeruli was associated with the level of proteinuria $(2,6,7)$. Another report on AA amyloidosis showed that the distribution pattern of glomerular amyloid deposits was closely associated with the level of proteinuria; mesangiocapillary deposition tends to have massive proteinuria whereas hilar deposition has a lower proteinuria level (10). Shiiki et al. (11) suggested a good correlation between glomerular amyloid distribution patterns and chemical types of amyloidosis. In the mesangial nodular pattern, deposited amyloid was almost invariably AA protein, whereas cases with mesangio-capillary and epimembranous patterns cases were AL amyloidosis-predominant. Unlike in the present case, the hilar pattern is often seen in patients with AA amyloidosis.

Amyloid deposition is not limited to the glomeruli but also occurs in the vasculature and the interstitial area of the kidney. As such, an impaired renal function is often associated with a mild degree of proteinuria. A previous case with vascular-limited AL amyloid deposition was described as having less proteinuria and more severe renal insufficiency (12). Similarly, predominant AA amyloid deposition in the vasculature with vascular-pole-limited deposition in the glomeruli was associated with a low proteinuria level, and the impairment of the kidney function was the initial clinical clue of renal involvement (10). Kidney dysfunction was reported to be associated with inflammatory cell infiltration and tubular casts (2), tubular atrophy, and arteriolar amyloid deposition (10). Castano et al. reported that cases with severe vascular amyloidosis presented with a high degree of inflammatory cell infiltration, as the proximity of vascular amyloid deposits to the capillaries tends to cause inflammatory reactions (7).

Dominant sites of amyloid deposition other than the glomeruli are often described in AA amyloidosis. Cases with AA amyloidosis had high grades of tubulointerstitial and vascular damage (13). Amyloid deposition was limited around vessels and absent in the glomeruli in $28.9 \%$ of AA amyloidosis patients (14). However, Hopfer et al. reported that there were no differences in the distribution of amyloid depositions between AL and AA types (6). Some chemicophysical properties of the amyloid fibrils have been suggested to be associated with the distribution patterns within the renal compartments, but the precise mechanism has not been established (6).

In our case, vascular depositions of AL amyloid, including glomerular hilar depositions extending to mesangial areas, were the dominant feature, accompanied by severe tubulointerstitial damage. The findings did not support tubulointerstitial nephritis caused by Sjögren's syndrome or light-chain cast nephropathy. Interstitial amyloid deposition was scarce. Ischemic changes due to progressive amyloid deposition in the vasculatures may be the major cause of the deterioration of the renal function in our case.

There have been several reports concerning the coexistence of primary Sjögren's syndrome and amyloidosis. However, most of them were nodular amyloidosis, mostly localized to the dermis (15) or lung (16). To the best of our 
knowledge, there has been only one report of a concomitant diagnosis of Sjögren's syndrome and systemic AL amyloidosis (17). Unfortunately, the lack of lacrimal or salivary gland biopsy could not preclude the possibility of the involvement of amyloid deposition in the targeted tissues in our case.

In summary, we herein reported a case of systemic AL amyloidosis with renal involvement, predominantly in the vasculatures, that had been strongly suspected of being interstitial nephritis due to Sjögren's syndrome before a pathological examination by renal biopsy. Clinicians should take into account the possibility of renal amyloidosis, even if patients show a clinical presentation of interstitial nephritis without massive proteinuria.

The authors state that they have no Conflict of Interest (COI).

\section{Acknowledgement}

We would like to thank Hiromi Yamaguchi for her valuable technical assistance.

\section{References}

1. Sun Y, Sandhu A, Gabaldon D, Danaraj J, Servilla KS, Tzamaloukas AH. Development of renal failure without proteinuria in a patient with monoclonal gammopathy of undetermined significance: an unusual presentation of AL kappa amyloidosis. Case Rep Nephrol 2012: 573650, 2012.

2. Yao Y, Wang S, Zhang Y, Qu Z, Liu G, Zou W. A clinicopathological analysis in a large cohort of Chinese patients with renal amyloid light-chain amyloidosis. Nephrol Dial Transplant 28: 6689-6697, 2013.

3. Petri M, Orbai AM, Alarcón GS, et al. Derivation and validation of the Systemic Lupus International Collaborating Clinics classification criteria for systemic lupus erythematosus. Arthritis Rheum 64: 2677-2686, 2012.

4. Gertz MA, Comenzo R, Falk RH, et al. Definition of organ involvement and treatment response in immunoglobulin light chain amyloidosis (AL): a consensus opinion from the 10th International Symposium on Amyloid and Amyloidosis. Am J Hematol 79: 319328, 2005.

5. Maripuri S, Grande JP, Osborn TG, et al. Renal involvement in primary Sjögren's syndrome: a clinicopathologic study. Clin J Am Soc Nephrol 4: 1423-1431, 2009.
6. Hopfer H, Wiech T, Mihatsch MJ. Renal amyloidosis revisited: amyloid distribution, dynamics and biochemical type. Nephrol Dial Transplant 26: 2877-2884, 2011.

7. Castano E, Palmer M, Vigneault C, Luciano R, Wong S, Moeckel G. Comparison of amyloid deposition in human kidney biopsies as predictor of poor patient outcome. BMC Nephrol 16: 64, 2015.

8. Said SM, Sethi S, Valeri AM, et al. Renal Amyloidosis: origin and clinicopathologic correlations of 474 recent cases. Clin J Am Soc Nephrol 8: 1515-1523, 2013.

9. Itabashi M, Takei T, Tsukada M, et al. Association between clinical characteristics and AL amyloid deposition in the kidney. Heart Vessels 25: 543-548, 2010.

10. Verine J, Mourad N, Desseaux K, et al. Clinical and histological characteristics on renal AA amyloidosis: a retrospective study of 68 cases with a special interest to amyloid-associated inflammatory response. Hum Pathol 38: 1798-1809, 2007.

11. Shiiki H, Shimokama T, Yoshikawa $Y$, et al. Renal amyloidosis. Correlations between morphology, chemical types of amyloid protein and clinical features. Virchows Arch A Pathol Anat Histopathol 312: 197-204, 1988.

12. Eirin A, Irazabal MV, Gertz MA, et al. Clinical features of patients with immunoglobulin light chain amyloidosis (AL) with vascular-limited deposition in the kidney. Nephrol Dial Transplant 27: 1097-1101, 2012.

13. Sasatomi Y, Kiyoshi Y, Uesugi N, Hisano S, Takebayashi S. Prognosis on renal amyloidosis: a clinicopathological study using cluster analysis. Nephron 87: 42-49, 2001.

14. Uda H, Yokota A, Kobayashi $\mathrm{K}$, et al. Two distinct clinical courses of renal involvement in rheumatoid patients with AA amyloidosis. J Rheumatol 33: 1482-1487, 2006.

15. Yoneyama K, Tochigi N, Oikawa A, Shinkai H, Utani A. Primary localized cutaneous nodular amyloidosis in a patient with Sjögren's syndrome; a review of the literature. J Dermatol 32: 120-123, 2005

16. Rajagopala S, Singh N, Gupta K, Gupta D. Pulmonary amyloidosis in Sjögren's syndrome: a case report and systematic review of the literature. Respirology 15: 860-868, 2010.

17. Delèvaux I, André M, Amoura Z, Kémény JL, Prette JC, Aumaître O. Concomitant diagnosis of primary Sjögren's syndrome and systemic AL amyloidosis. Ann Rheum Dis 60: 694-695, 2001.

The Internal Medicine is an Open Access article distributed under the Creative Commons Attribution-NonCommercial-NoDerivatives 4.0 International License. To view the details of this license, please visit (https://creativecommons.org/licenses/ by-nc-nd/4.0/).

(C) 2017 The Japanese Society of Internal Medicine http://www.naika.or.jp/imonline/index.html 